\title{
Lean Thinking by integrating with Discrete Event Simulation and Design of Experiments: an emergency department expansion
}

\author{
Gustavo Teodoro Gabriel ${ }^{\text {Corresp., }}{ }^{,}$, Afonso Teberga Campos ${ }^{1}$, Aline de Lima Magacho ${ }^{1}$, Lucas Cavallieri Segismondi ${ }^{1}$, \\ Flávio Fraga Vilela ${ }^{1}$, Jose Antonio de Queiroz ${ }^{1}$, José Arnaldo Barra Montevechi ${ }^{1}$ \\ 1 Industrial Engineering and Management Institute, Federal University of Itajubá, Itajubá, Minas Gerais, Brazil \\ Corresponding Author: Gustavo Teodoro Gabriel \\ Email address: gustavo.teodoro.gabriel@gmail.com
}

Background. Many management tools, such as Discrete Event Simulation (DES) and Lean Healthcare, are efficient to support and assist health care quality. In this sense, the study aims at using Lean Thinking (LT) principles combined with DES to plan a Canadian emergency department (ED) expansion and at meeting the demand that comes from small care centers closed. The project's purpose is reducing the patients' Length of Stay (LOS) in the ED. Additionally, they must be assisted as soon as possible after the triage process. Furthermore, the study aims at determining the ideal number of beds in the Short Stay Unit (SSU). The patients must not wait more than 180 minutes to be transferred.

Methods. For this purpose, the hospital decision-makers have suggested planning the expansion, and it was carried out by the simulation and modeling method. The emergency department was simulated by the software FlexSim Healthcare ${ }^{\circledR}$, and, with the Design of Experiments (DoE), the optimal number of beds, seats, and resources for each shift was determined. Data collection and modeling were executed based on historical data (patients' arrival) and from some databases that are in use by the hospital, from April $1^{\text {st }}, 2017$ to March $31^{\text {st }}, 2018$. The experiments were carried out by running 30 replicates for each scenario.

Results. The results show that the emergency department cannot meet expected demand in the current state. Only $17.2 \%$ of the patients were completed treated, and LOS was 2213.7 (average), with a confidence interval of (2131.8-2295.6) minutes. However, after changing decision variables and applying LT techniques, the treated patients' number increased to 95.7\% (approximately 600\%). Average LOS decreased to 461.2, with a confidence interval of (453.7-468.7) minutes, about $79.0 \%$. The time to be attended after the triage decrease from 404.3 minutes to 20.8 (19.8-21.8) minutes, around 95.0\%, while the time to be transferred from bed to the SSU decreased by $60.0 \%$. Moreover, the ED reduced human resources downtime, according to Lean Thinking principles. 
1 Lean thinking by integrating with Discrete Event Simulation and design of 2 experiments: an emergency department expansion

3 Gustavo Teodoro Gabriel ${ }^{1}$, Afonso Teberga Campos ${ }^{1}$, Aline de Lima Magacho ${ }^{1}$, Lucas Cavallieri Segismondi ${ }^{1}$,

4 Flávio Fraga Vilela ${ }^{1}$, José Antonio de Queiroz ${ }^{1}$, José Arnaldo Barra Montevechi ${ }^{1}$

${ }^{1}$ Industrial Engineering and Management Institute, Federal University of Itajubá, Itajubá, Minas Gerais, Brazil

Corresponding Author:

Gustavo Gabriel ${ }^{1}$

Av. BPS, 1303, Itajubá, Minas Gerais, 37500-903, Brazil

Email address: gustavo.teodoro.gabriel@gmail.com

\section{Abstract}

Many management tools, such as Discrete Event Simulation (DES) and Lean Healthcare, are efficient to support and assist health care quality. In this sense, the study aims at using Lean Thinking (LT) principles combined with DES to plan a Canadian emergency department (ED) expansion and at meeting the demand that comes from small care centers closed. The project's purpose is reducing the patients' Length of Stay (LOS) in the ED. Additionally, they must be assisted as soon as possible after the triage process. Furthermore, the study aims at determining the ideal number of beds in the Short Stay Unit (SSU). The patients must not wait more than 180 minutes to be transferred. For this purpose, the hospital decision-makers have suggested planning the expansion, and it was carried out by the simulation and modeling method. The emergency

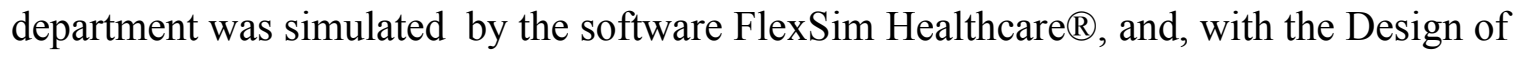
Experiments (DoE), the optimal number of beds, seats, and resources for each shift was determined. Data collection and modeling were executed based on historical data (patients' arrival) and from some databases that are in use by the hospital, from April 1 15t, 2017 to March $31^{\text {st }}, 2018$. The experiments were carried out by running 30 replicates for each scenario. The results demonstrate that the emergency department could not meet the expected demand in its first approach. Only $17.2 \%$ of the patients were fully treated, and the LOS was 2213.7 minutes (on average), with a confidence interval of (2131.8-2295.6) minutes. However, after changing decision variables and applying $\mathrm{LT}$ techniques, the number of treated patients increased to $95.7 \%$ (approximately $600 \%$ ). The average LOS decreased to 461.2 , with a confidence interval of (453.7-468.7) minutes, about $79.0 \%$. The time to be assisted attended after triaged decreased from 404.3 minutes to $20.8(19.8-21.8)$ minutes, around $95.0 \%$, while the time to be transferred 
34 from bed to the SSU decreased by $60.0 \%$. Moreover, the ED reduced human resources

35 downtime, according to Lean Thinking principles.

36

37

38

39

40

41

42

43

44

45

46

47

48

49

50

51

52

53

54

55

56

57

58

59

60

61

62

63

\section{Introduction}

Improvements in the health services quality sector are significant because it directly affects the patient's satisfaction and safety. In fact, the health industry is one of the largest in the world (Bhat, Gijo, and Jnanesh, 2014). According to (World Bank, 2019), in 2016, the world spending on health was around $10.0 \%$ of total GDP. The United States was the country who invested the most per capita, totaling US\$9,869.74, followed by Switzerland. Canada is among the top 20 countries who invest in health per capita, US\$ 4,458.21 in total, against the world average of 1,025.29 (World Bank, 2019).

Given the importance of the world health system, decision-makers seek out solutions to make more efficient and agile processes. Besides that, financial resources and skilled labor are becoming scarce. Consequently, decision-makers apply management tools for analysis and process improvements in forecasting, restructuring, and reducing costs. Indeed, many real problems are really complex. Rarely one single approach or tool is enough to reach solutions (Brailsford et al., 2018).

Discrete Event Simulation (DES) is one of the tools used to improve it and forecast process behavior. DES is the imitation of a dynamic process, using a computer model for evaluating, measuring and improving the performance of any system (Harrell, Ghosh \& Bowden, 2012) without any physical risks and additional costs (Banks et al., 2010; Montevechi et al., 2007). Moreover, the literature defines DES as the model development process (hypothetical or real) aiming at performing experiments (Negahban \& Yilmaz, 2014). Hence, predicting the behavior of real and complex systems becomes a really tough challenge, because they are influenced by a set of internal and external factors, and the experience is often unfeasible to perform (Budgaga et al., 2016). Therefore, DES is the first step in evaluating a change proposal, obtaining insight into a set of potential impact, and supporting management to make decisions and implement realworld improvements (Bem-Tovim et al., 2016; Dengiz \& Belgin, 2014).

In addition to DES, Lean Manufacturing is also efficient in improving processes. Lean emerged in the 1950s when the Japanese automotive industry faced a challenging scenario. The market was limited and a wide variety of vehicles were demanded. It was in contrast to the current 
64 philosophy of mass production until then (few varieties produced on a large scale). Furthermore, 65 Japan`s economy was weakened, with low capital availability and few international trade

66

67

68

69

70

71

72

73

74

75

76

77

78

79

80

81

82

83

84

85

86

87

88

89

90

91

92

93

94

relations. Also, the acquisition of modern western production technologies became harder

(Womack, Jones \& Roos, 1990). To meet this challenge, the Japanese automaker company

Toyota began developing a new system of production, the Toyota Production System (TPS).

Taiichi Ohno, credited as the facilitator of the TPS, aimed to serve customers in the shortest time, at the highest quality and the lowest possible costs. Thereby, it would be necessary to focus all effort on activities that add value to the customer and eliminating wastes (Graban, 2016).

Over time, Lean has expanded throughout other sectors, such as healthcare, which has been renamed to Lean Healthcare (LH).

Finding wastes in manufacturing has been adapted to health services. Defects correspond to poor medication administration or incorrect doses, while overproduction characterizes as unnecessary diagnostic procedures. Inefficient transportation is inadequate layouts and laboratories away from collection points. The inappropriate layout may also link to the unnecessary movement of nurses and doctors. Waiting features idle employees with uneven workloads and patients waiting for service. The stock is characterized as expired supplies and super-processing, e.g., data in the patient registry that will not be used later (Graban, 2016).

Finally, performing experiments with DES is essential for the analysis of the current scenario and for proposing improvements. The experiment is indicated when the modeler desired to optimize the process (Banks et al., 2010). A good experiment demand to set the parameters so the responses may approach the required values with the lowest variability (Montgomery \& Runger, 2018). The best way to evaluate several factors in a process is by using suitable techniques to plan the experiments, e.g., factorial experiments, Taguchi, and Plackett-Burman (Montgomery \& Runger, 2018). In this case, the factors change simultaneously, observing if there is an interaction between them. Moreover, it generally requires fewer tests than the "best guess" strategy, where the expert performs random experiments. According to (Banks et al., 2010), with some adaptations in the factorial arrangements, we may evaluate the individual, interactions, and quadratic effects.

Thereby, the three presented techniques, when used together, show effective results in health processes. In this sense, this study aims to plan the expansion of a Canadian emergency department (ED). The expansion is necessary because four nearer small centers were closed and

Peer] Comput. Sci. reviewing PDF | (CS-2019:08:40076:3:1:NEW 25 Jun 2020) 
95 all the patients needed to be attended to in the new ED. According to LH principles, the study 96 aims to define the ideal number of resources, beds for care, and beds in the Short Stay Unit 97 (SSU). The project purposes of reducing the patients' Length of Stay (LOS) in the ED. 98 Additionally, they must be taken care of as soon as possible after going through the triage. 99 Furthermore, it is necessary to determine the ideal number of SSU beds because the patients 100 should not wait for more than 180 minutes for their transfer.

101 In order to contribute to the literature, the study uses the Design of Experiments (DoE) to 102 determine the resource numbers influence on each shift, in addition to identifying the main 103 limiting factors of physical resources for the ED expansion. The simulation also allows 104 evaluating the influence of demand variation throughout the day and week in the future scenario. 105 The paper is divided as follows: the next section presents a literature review of DES and Lean in 106 hospital environments, followed by the methodology. The subsequent sections present the results 107 and discussions to conclude the study.

108

109

110

111

112

113

114

115

116

117

118

119

120

121

122

123

124

\section{Literature Background}

This section describes the studies that used Discrete Event Simulation and Lean Healthcare to improve the healthcare sector. Moreover, this section presents the two main tools used in our paper, the IDEF-SIM technique and the Design of Experiments.

\subsection{Discrete Event Simulation and Lean in healthcare systems}

Performing DES in healthcare is not new, dating back to the 1960s (Pitt, 2008). However, since then, there has been considerable growth for its interest. According to (Arisha \& Rashwan, 2017), this progress is strong evidence that the simulation provides better decisions in health services management without compromising patient safety. This advantage has increasingly attracted the attention of hospitals and health authorities (Cheng et al., 2017). However, experts in healthcare simulation claim that its use is more complicated than in other areas (Tako \& Robinson, 2015). The main problems found in the healthcare simulation are less evident structure; the system is complex; more significant effort to collect and access data; barriers due to ethical issues; client's shortage of time; and more difficulty in ensuring implementation. Despite the difficulties, it is possible to find studies with positive results linked to costs, capacity, wait and stay time, and levels of service and losses. (Zhou \& Olsen, 2018) applied DES for 
125 medical supplies management and decreased the costs involved in the process by reducing 126 expired drugs. (Hussein et al., 2017) presented effective results reducing overcrowding in a 127 hospital. Similar results were shown by (Babashov et al., 2017) and (Shim \& Kumar, 2010) by 128 decreasing patients' waiting time in an emergency department. (Rau et al., 2013) and (Uriarte et 129 al., 2017) also used DES to reduce patient waiting time in treatment centers and the radiotherapy sector, respectively. Furthermore, (Al-Araidah, Boran \& Wahsheh, 2012) applied the tool in an ophthalmology laboratory to decrease patients' waiting and appointment time. Regarding planning and capacity analysis, (Pinto et al., 2015) defined the ideal number of beds for a Brazilian hospital. In the balancing of staff work, (Reynolds et al., 2011) applied the simulation to reduce the workload of an English pharmacy and (Pongjetanapong et al., 2019) used the tool to evaluate the change effect to staff levels in a cytology department. Although these studies present positive results, we found some limitations in them. Some papers did not consider variables and statistical distributions for different workgroups (Reynolds et al., 2011) and processes (Rau et al., 2013). (Pinto et al., 2015) state that the simulation results have a slight underestimation, although it seems reliable and more effective for decision making than empirical calculations. Although articles use powerful tools jointly with DES, some studies do not test the interaction of resources, locations, and factors using the "best guess" approach (AlAraidah, Boran \& Wahsheh, 2012; Uriarte et al., 2017). In contrast, (Hussein et al. 2017) use DoE to observe the interaction of two factors in their scenarios. Nevertheless, they did not observe the interaction in the resource number in each shift (present in this study). (Shim \&

145 Kumar, 2010) state that the simulation did not take into account the varying resource capacities 146 (doctors and nurses) and locations (workstations from the sorting station to the payment station) 147 involved in the emergency care process. Finally, (Babashov et al., 2017) use simulation to 148 determine the average waiting time for all patients overall, not for each patient type.

149 It was also possible to verify improvements using only LH. Even when not implemented systematically and comprehensively in the organization, LH can provide several benefits to health services (D'Andreamatteo et al., 2015). Among these benefits, the authors highlight improvements in productivity, costs, financial results, quality of service delivery, and patient and team safety and satisfaction. However, implementing Lean is long-lasting and challenging work in the health sector (Toussaint \& Berry, 2013). Lean transform the organizational culture from 
155 the inside out, requiring managers and leaders to become facilitators, mentors, teachers, and 156 enable employees to take the initiative in making improvements.

157 Studies that show LH implementation can be found for the elimination of processes that do not 158 add value to the patient (Teichgräber \& De Bucourt, 2012) and reduction in the instrument 159 collection stage (Kimsey, 2010). (Laganga, 2011) used lean methodology to increase patient care 160 capacity, while (Papadopoulos, Radnor \& Merali, 2011) used LH to reduce delays in receiving 161 samples, prioritize urgent work, standardize processes and anticipate problem identification. 162 Although LH application is useful and essential in waste elimination and increasing patient 163 value-added time, it can be time-consuming, and the staff involved may resist the methodology. 164 When used jointly, Lean and DES have three goals: to teach, evaluate, and facilitate the process. 165 In order to evaluate, it allows the execution of experiments and the evaluation of their results. It 166 should be employed after holding a team meeting, testing ideas, and creating new solutions 167 (Robinson et al., 2012). The use of DES and LH in hospital settings may bring more quality and 168 efficiency to patients and management (Gaba, 2004). Also, the patient flow may be optimized 169 and served as a motivational factor for employees (Salam \& Khan, 2016). (Swick et al., 2012) 170 state that hospitals that integrate these tools offer an efficient method of strategic planning and 171 provide employees with a privileged view of how to reduce waste and add value. Moreover, it is 172 possible to reduce patients' waiting time, decreasing employee workload, and promoting resource 173 reallocation (Haddad et al., 2016; Bhat, Gijo \& Jnanesh, 2014). Finally, (Doğan \& Unutulmaz, 174 2016) and (Robinson et al., 2014) used the tools to transform static mappings into dynamic.

175 Some limitations were found in these studies. (Salam \& Khan, 2016) did not use arrival and staff 176 modeling. (Swick et al., 2012) limited the work to the daytime hours (more considerable 177 resources demand), and there was no adjustment for the night shift. (Bhat, Gijo \& Jnanesh, 2014) 178 conducted the study in an environment where patient arrival cannot be adequately controlled. 179 (Haddad et al., 2016) conducted the study limited to a process that ignores interdependencies 180 with internal and external parts and laboratory tests. (Doğan \& Unutulmaz, 2016) used only 181 Value Stream Mapping and did not carry out planned experiments.

\section{2.2. IDEF-SIM Technique}

183 The IDEF-SIM (Integrated Definition Methods - Simulation) process mapping technique was 
185 186

187

188

189

190

191

192

193

194

195

196

197

198

199

200

201

202

203

204

205

206

207

208

209

210

211

212

213

214

and analysis phase, reducing project time. The IDEF-SIM was created based on existing logical elements in other mapping techniques, such as IDEF0, IDEF3 and flowchart (Peixoto et al., 2017; Montevechi et al., 2010). To our best knowledge, there is no history of this technique used in healthcare systems, although we have found in manufacturing (Pereira et al., 2015; Montevechi et al., 2010) and transports (Lopes et al., 2017). Nevertheless, we chose to use this technique because the symbols are directly translated from the conceptual model for the computer model, presenting elements of the simulation, e.g., entities, locations, resources, functions, controls, logical rules, and transport (Pereira et al., 2015). The symbols used in the IDEF-SIM are (Peixoto et al., 2017; Montevechi et al., 2010):

a) Entity (circle): items processed in the system, e.g., raw materials, products, people.

b) Functions (rectangle): places where entities change or have delays, e.g. workstations, conveyors, queues, stocks, beds, waiting lines.

c) Entity flow (arrow): direction that the entities follow in the model.

d) Resources (arrow under the rectangle): elements that move the entities or perform the functions, e.g. people, such as operators, nurses, doctors.

e) Controls (arrow above the rectangle): rules used in the functions, e.g. rules of scheduling, queuing, sequencing.

f) Movement (large arrow): it is used when there is a significant entity displacement.

g) Explanatory information (dashed arrow): it is used to include some explanation.

h) Rules for parallel and/or alternate flows: entities must follow in parallel (AND - "\&"); alternatively (OR - “X”); or in parallel and/or alternate paths (AND/OR - “O”).

i) Input flow (initial arrow): determines the input or entities' creation.

j) End of the system (painted circle): determines the end of a path.

k) Connection with another figure (triangle): divide the model into different figures.

\subsection{Design and Analysis of Experiments}

Design of Experiment (DoE), is considered one of the most relevant methodologies for researchers performing applicable experiments. Moreover, according to Montgomery (2017), DoE is a collection of statistical techniques capable of generating and analyzing experimental projects in which several factors are varied at the same time. In DoE, the modeler chooses different levels for the independent variable and can vary the factors simultaneously to study the 
215 effects in the responses (dependent variables). These effects can be separate from each

216 independent variable or the interaction between them (Baril, Gascon \& Vadeboncoeur, 2020).

217 When experimental designs are appropriately designed, trial and error analysis are avoided. Also,

218 it is possible to detect unimportant factors and simplify the simulation model. Among DoE

219 techniques, the $2^{\mathrm{k}}$ factorial design is used as it requires few executions per factor, and data 220 interpretation can proceed mainly through arithmetic and graphs. In DoE, $k$ value is the number

221 of factors that presented the upper (+) level and lower (-) level. In the literature, many studies use 222 DoE to plan and dimension resources around healthcare systems and EDs. (Baril, Gascon \& 223 Vadebonceur, 2019) used the DoE to vary the number of doctors, nurses and beds to decrease 224 LOS in Canada. (Bhattacharjee \& Ray, 2018) used DoE and DES to gain insights into 225 appointment scheduling. Moreover, (Gul, Guneri, \& Gunal 2019) dimensioned an emergency 226 department to support natural disasters analyzing the number of nurses and doctors. Although 227 these articles use DoE, our study is different because we use DoE to dimension beds and the 228 number of resources in each shift.

229

230

231

232 233

234

235

236

237

238

239

240

241

242

243

\section{Materials \& Methods}

Modeling and simulation, used in the study, comprises three phases: design, implementation, and analysis (Montevechi et al., 2010). In the first phase, i.e., design, we should formulate the problem. In this step, we define the process to be modeled, actions and goals. The second step is the conceptual model building, validation, and documentation. It is possible to use many languages, but opting for a simulation-oriented is desirable (Montevechi et al., 2010). The last stage is the input data modeling, e.g., time, cost, percentages, capacities, varying according to the study (Banks et al., 2010; Montevechi et al., 2010).

The second major phase, implementation, covers the steps of computer model building, verification, and validation. The modeler must use familiar software for computer model building. Thus, it is performed the verification, ensuring that the computer model programming corresponds to the conceptual model (Sargent, 2013). Finally, it is carried out the validation through hypothesis tests, confidence intervals, or sensitivity analysis (Sargent, 2013).

For the analysis, the modeler starts the planning, construction, and analysis of the experiments. In this step, the modeler defines possible scenarios, besides the use of experiment planning and 
244 statistical tests (Montgomery \& Runger, 2018). After the experiments, the scenarios are 245 analyzed, and the team obtains the conclusions and answers to the problem.

246 Based on the three major steps described, we conduct the study as follows:

247 (1) Conceptual Modeling: we developed the conceptual model using the IDEF-SIM

248

249

250

251

252

253

254

255

256

257

258

259

260

261

262

263

264

265

266

267

268

269

270

271

272 technique. We choose this language because it is considered specific for DES, facilitating computer programming (Montevechi et al., 2010).

(2) Computer Modeling: we used FlexSim Healthcare ${ }^{\circledR}$ software.

(3) Model Execution and initial analysis: we performed replicas to confirm the patient and the hospital unit's performance measure in the current scenario. These executions allowed us to choose the first set of DoE decision factors.

(4) Design and analysis of experiments: we chose a complete factorial design because it requires few runs per factor and a better fit model. It was carried out a DoE to find out the ideal number of employees at each shift.

(5) Confirmation runs: the optimal values of the decision variables found in the experiments were used in the model to confirm the results.

\section{Results and Discussion}

\subsection{Case Study}

Cape Breton Regional Hospital (CBRH) is one of four facilities that make up the Cape Breton Health Care Complex, a Canadian public health network of four hospitals, serving approximately 100,000 inhabitants. This paper aims to plan the expansion of a Canadian ED to meet the demand that comes from the small closed care centers. The exponential increase in demand is due to the closure of these small service units in locations near the CBRH.

Regarding the patients` flow, they arrive at the ED by themselves or by ambulance. Both are triaged and ranked according to severity. This classification is given according to the Canadian Triage Acuity Scale (CTAS). CTAS level I corresponds to the most severe level, resuscitation (blue, to be seen immediately); level II is emergent (red, to be seen $<15$ minutes); level III is urgent (yellow, to be seen $<30$ minutes); Level IV is less urgent (green, to be seen $<60$ minutes) and level $\mathrm{V}$ is non-urgent patient (white, to be seen $<120$ minutes). Patients arriving by ambulance, after triage, go straight to care. Patients who arrive on their own go to the registry 
273 and expect the transfer to their appointment. CTAS level I, II, and III patients go to a bed area 274 (45 beds and 3 for mental health), while CTAS IV and V follow to the vertical area (10 seats). 275 When the patient arrives at the bed area (BA) or the vertical area (VA), he undergoes two 276 evaluations made by the nurse and the physician. Then the ward clerk receives and records the 277 patient's prescription. These prescriptions may include laboratory tests (blood, urine), medical 278 procedures, and diagnostic imagining (DI). Such procedures are assigned according to the 279 patient's category, shown in Table 1. If DI is required, a nurse and a porter must escort CTAS 280 level I patients. For other patients, only the porter is required.

281

282 283

284 285 286

287 288 289

290

291

292

293

294

295

296

297

298

299

300

301

302

303

\section{Table 1. Patient's category and specialist}

After waiting for the exam results, the patient may go through an appointment with a specialist or move on to the next stage. If the patient goes through the appointment, he must wait until the specialist arrives, since they are not in the ED. In the next step, the patient may be discharged or go through monitoring. After monitoring, the patient goes to the SSU (10 available beds), where it can remain from one to three days.

The ED Nurses are divided into two teams. The first team is responsible for patients CTAS level I and II (EDN1), and the second is responsible for CTAS level III, IV, and V (EDN2). They work in four shifts: 07:00 a.m. to 07:00 p.m.; 09:00 a.m. to 09:00 p.m.; 11:00 a.m. to 11:00 p.m. and 07:00 p.m. to 07:00: a.m. Physicians and Triage Nurse (TN) start working at the same shifts. In addition, three porters work in the following shifts: 07:00 a.m. to 07:00 p.m.; 10:00 a.m. to 06:00 p.m. and 07:00 p.m. to 07:00 a.m.

The study aims to analyze whether the ED can absorb the full demand from the closures. Other issues to be solved are ideal numbers of resources (TN, EDN, physicians, and porters); the ideal number of beds in BA, chairs in VA and beds in SSU; reduction in the time of care after going through the triage, in the time to transfer from BA/VA to SSU and LOS. In this sense, the decisionmakers from the hospital proposed an approach to be tested by the simulation, called Initial Planning (IP). We used DES because patients are individual entities with particular characteristics, and the procedural flow depends on the CTAS of each one. Moreover, we chose DES over System Dynamics because it has the most relevant characteristics of the work responses. We can say that DES is better in decision-making, prediction, optimization, and comparison; it behaves well for high rates of change and presents the high importance of tracking individuals. In addition, it is suitable for systems with few entities and relatively small-time scales (Brailsford \& Hilton, 2001). 
304

305

306

307

308

309

310

311

312

313

314

315

316

317

318

319

320

321

322

323

324

325

326

327

328

329

330

331

332

333

\subsection{Conceptual Modeling}

We performed the conceptual modeling of the system through the IDEF-SIM language. Figure 1 shows the patient flow. We do not present percentages for each process because there are many combinations based on the disease category and CTAS level.

Figure 1. Conceptual Modeling

As mentioned in section 2.2, the first circle represents the entities in the model, i.e., patients.

Rectangles mean delays in patient flow or procedure waiting (queue, exam results). Large arrows represent transport for the patient, e.g., an exam performed in another room. Processes that need a nurse or doctor are indicated with an arrow at the bottom of the rectangle, while the upper arrows are controls. Symbols with an "x" inside them indicate an option (OR connection), while symbols with an "\&" represent an obligation (AND condition). The diamonds represent a stopping point. The entity only follows the flow if the given conditions have been met. In the model, the patient only continues the flow if the test results are ready, and there is an evaluation by a doctor and a nurse. We ensure that the conceptual model presents high reliability since it was validated by face-to-face validation, where experts verify if the model matches the real system (Kleijnen, 1995; Sargent, 2013).

\subsubsection{Data set}

Data collection and modeling were based on historical data (patients' arrival) and from some databases that are used in the hospital from April 1 ${ }^{\text {st }}, 2017$ to March 31 $1^{\text {st }}$, 2018. Through the historical data, we observed that patients arrive at different rates hourly and daily. These rates are repeated weekly. As soon as a patient is screened in the emergency room their information is entered into the system. After that, Medietch ${ }^{\circledR}$ is used for registration, diagnostic codes, CTAS level, treatment time, diagnostic test ordering, and blood exams. Figure 2 shows the patient's arrival rate based on weekday and the two-hour scale.

Figure 2. Arrival rate for each patient CTAS level

We notice that the curves show similarity in the shape where the number of patients starts to increase from 08:00 a.m. Moreover, the curves present a peak between 10:00 a.m and 12:00 p.m. The days with the highest arrival rates are Tuesday, Wednesday and Thursday. Regarding the type of patient, the curves do not differ significantly, showing the same behavior throughout the day and week. Patients of CTAS level III and IV are predominant in the ED. As shown in Figure 
334 1, the patient may be admitted for SSU placement or be discharged. Each of these stages

335 involves different resources, such as doctors, nurses, porters, and the patient suffers a delay

336 (process time). These times were estimates from the ED manager and nurses through Delphi

337 method (Table 2).

338

339

340

341

342

343

344

345

346

347

348

349

350

351

352

353

354

Table 2. Processing Time and required staff

As previously stated, ED patients may require a sample, consultation and/or lab work. The patients may carry out a sample, e.g., blood work (BW) and specimen (SP). In addition, patients may have DI exams, such as X-Ray (XR), electrocardiogram (EKG), echocardiogram (ECHO), computerized tomography (CT), and ultrasonography (US) according to the CTAS level and patient's category (Table 1). Table 3 summarizes the probability if the patient needs an exam.

Table 3. Exam probability for each CTAS level

There is a probability of the patient having an appointment with one or two specialists. Moreover, when the patient needs an appointment with an expert, some response delay can happen according to the specialist and the CTAS patient level. This delay occurs because the specialist is not staffed in the ED unit all the time. They release the patient to the attending physician while consulting the patient unless they are CTAS level I. After a specialist arrives in the ED to consult with a patient, he attends all patients that need him, from lowest to highest CTAS level. The specialist will start a new consult any time before the end of their shift. Any patients still in need of a consult at the end of the day will be seen by Internal Medicine or wait until the beginning of a specialist's shift the following day to receive an appointment. Internal Medicine covers cardiology, nephrology and gastroenterology. Table 4 describes these data.

Table 4. Specialist probability appointment for each CTAS level and data set

\subsection{Computer Modeling}

We designed the computer model in FlexSim Healthcare ${ }^{\circledR}$ software, programming three different processes. First, we programmed patient flow according to CTAS levels, because each level may indicate different paths and require different resources. The second process involves the procedures exam, from sample collection to the end result. It directly impacts the patient waiting time, since it can only follow through the flow after the results, characterizing a necessary time, but that does not add value for them. Finally, we construct global processes, such as staff meetings that affect patients' waiting time and must be reduced to a sufficient level. Figure 3 shows the computer model designed for the current scenario.

Peer] Comput. Sci. reviewing PDF | (CS-2019:08:40076:3:1:NEW 25 Jun 2020) 
365

366

367

368

369

370

371

372

373

374

375

376

377

378

379

380

381

382

383

384

385

386

387

388

389

390

391

392

393

394

Figure 3. Computer model screen in the FP scenario

After the model was built, we performed a verification process. The process was conducted through a face-to-face technique for each CTAS level. The specialists and the modeling team analyzed the simulated model and agreed that it was as close to the real patient flow as possible. We also performed the validation. If the modeled system is a non-observable system, it is recommended using a subjective approach (Sargent 2013; Sargent, Goldsman \& Yaacoub, 2016). In this sense, we carried out a sensitivity analysis to see the model variability. We have tested patient arrival rates at five levels: $100 \%, 75 \%, 50 \%, 25 \%$ and $10 \%$. We got the mean LOS and the percentage of treated patients to perform the validation. For LOS, in minutes, the simulations show: 2213.7 (100\%), 428.2 (75\%), 352.9 (50\%), 270.9 (25\%), 243.4 (10\%). We expected to increase the number of patients, LOS would increase in the same way. This situation occurs because the patients have to wait more time for available resources. Although, if we are decreasing the arriving rate, the percentage of treated patients starts to increase because there are more staff available for each one. Figure 4 shows the sensitivity analysis for the validation.

Figure 4. Sensitivity analysis for validation (LOS and \% Treated Patient)

\subsection{Model Execution and Initial Analysis}

After the computer validation, the model was simulated for one week, and data were collected from Tuesday to Tuesday. A warm-up of one day (Monday) was necessary to get a stable process. Consequently, according to the computer simulation, the ED cannot meet the expected demand for IP. Moreover, the obtained results were:

- On average, 1504 patients arrived in the model;

- On average, 258 (17.2\%) patients were completed treated in the simulated period;

- Around 1157 patients (76.9\%) did not even make it triage;

- On average, LOS was 2213.7 minutes;

- Patients wait about 404.3 minutes to be seen after triage;

- Patients who need to go to SSU wait, on average, 367.4 minutes to be transferred.

Regarding the results, the number of patients that do not go through the risk classification is alarming. In addition, after triage, the average waiting time is around 404.3 minutes, which corresponds to approximately 3.5 times what the patient with CTAS level V should wait at most. Moreover, patients expect to be attended after the risk classification, on average 25.9, 164.6,

Peer] Comput. Sci. reviewing PDF | (CS-2019:08:40076:3:1:NEW 25 Jun 2020) 
$395332.2,649.7$ and 419.5 minutes for the CTAS levels I, II, III, IV, and V, respectively, which does 396 not meet the specifications.

397 The result is unsatisfactory and below the current quality standard offered by the hospital. We

398 conclude the initial ED planning for the possible scenario after closing the surrounding care

399 centers still has deficiencies. This reinforces the importance of using simulation to ensure that

$400 \mathrm{ED}$, in this scenario, continues to offer a high quality of care. Especially in disruptive situations

401 where planning becomes more difficult.

402 Moreover, for the initial analysis, most of the resources are idle, e.g., triage nurses and

403 physicians. Most nurses and porters are waiting for empty locations (beds and seats).

404 Consequently, the patient's flow is stuck. It other words, beds in the BA, MBA, SSU, and VA are

405 occupied most of the time.

406 In this sense, based on LT, some improvements have been proposed. These improvements aim to

407 reduce patient waiting time, thereby increasing the safety of their care. Therefore, we

408 investigated the interaction between places in the ED and the resources in the patient flow.

409 4.5. Design and Analysis of Experiments

410 4.5.1. Design and Analysis of Experiments for Locations

411 For the first set of experiments, we defined a complete factorial $2^{4}$, where the factors are the 412 number of beds in the SSU, Mental Bed Area (MBA), Bed Area (BA), and the number of seats in 413 the Vertical Waiting Area (VA). We estimated these numbers using Equation (1):

$$
Q_{i}=\frac{t_{i} * p_{i}}{60 \min }
$$

414 Where:

$415 \mathrm{Q}_{i}=$ Required number of location or staff per patient/hour;

$416 \mathrm{t}_{i}=$ Time in minutes that a patient stays in the area or needs a resource (average);

$417 \mathrm{p}_{i}=$ number of patients that arrives in area $i$ or needs a resource (average);

418 Thus, considering these variables, a full factorial design was planned. We choose a full factorial 419 design $\left(2^{4}=16\right.$ runs) since the number of runs is lower, and design reliability is higher than half 420 factorial $\left(1 / 2 * 2^{4}=8\right.$ runs). To determine the levels of DoE, we used a $20 \%$ margin of factor 421 target to define "level -" and "level +". The results were rounded down and up, respectively, and 422 are shown in Table 5. 
423

424

425

426

427

428

429

430

431

432

433

434

435

436

437

438

439

440

441

442

443

444

445

446

447

448

449

450

451

452

453
Table 5. Variables related to locations and DoE parameters

The performance measures defined in response to DoE were: (i) Weekly treated patients; (ii) LOS; (iii) Time for the patient to be attended after triage and (iv) Time to transport the patient to SSU. We chose to use this order in all analyses, since the number of treated patients is more important, followed by the time spent in the hospital.

The number of SSU beds was the factor that affects all the chosen metrics in a significant way. Based on Lenth's method, the number of beds and seats in SSU, BA, MBA, VA, and some interactions were identified as statistically significant. The factors interaction hinders the ED performance since the locations are used together in some specific points of the model. In this way, we did not remove any variable from the analyses.

In order to obtain fit meta-models to the system and to identify eventual curvatures in the objective functions, we chose to perform a Response Surface Methodology (RSM). Using this design, we got seven central points and four axial points, resulting in another 31 experiments. A central point test the model in the upper level, lower level, and the middle of these points. We analyzed the same performance measures and it was obtained an $\mathrm{R}^{2}$-adjusted fit of $90.6 \%$ for measure (i); $93.1 \%$ for (ii); $95.2 \%$ for (iii) and $98.6 \%$ for (iv) and a predicted $\mathrm{R}^{2}$ of $82.0 \%$; $72.7 \% ; 83.5 \%$ and $95.6 \%$, respectively. $\mathrm{R}^{2}$ refers to the degree of model reliability, and higher values indicate that the model better fits its data. The value of $\mathrm{R}^{2}$ is always between 0 and $100 \%$. Therefore, the results indicated the best factors combination is:

- 30 beds in SSU;

- 45 beds in BA;

- 5 beds in MBA;

- 15 seats in VA;

The model was replicated ten times under the same conditions as the IP scenario in order to verify the optimized response. In this case, the resources do not have a set shift. Thus, analyzing the same parameters, we observed:

- On average, 1505 patients arrived in the model;

- On average, $1436(95.4 \%)$ patients were completed treated in the simulated period;

- All patients make it triage;

- On average, LOS was 436.0 minutes;

- Patients wait about 25.7 minutes to be seen after triage;

PeerJ Comput. Sci. reviewing PDF | (CS-2019:08:40076:3:1:NEW 25 Jun 2020) 
454

455

456

457

458

459

460

461

462

463

464

465

466

467

468

469

470

471

472

473

474

475

476

477

478

479

480

481

482 - On average, 1442 (95.8\%) patients were completed treated in the simulated period;

- Patients who need to go to SSU wait, on average, 128.5 minutes to be transferred.

Compared to the IP scenario, all patients underwent triage, showing that patient flow became more continuous than in the first approach. Still, the number of treated patients increased by around $590 \%$. On the other hand, the waiting time to be attended after triage was an average of 25.7 minutes, 5.5 minutes for CTAS I, 11.0 minutes for CTAS II, 19.6 minutes for CTAS III, 37.5 minutes for CTAS IV and 40.9 for CTAS V.

Despite the increasing number of patients and the decreasing in LOS and waiting time to be attended after triage, the resources were not dimensioned. In other words, the staffs are still idle. Thus, the second scenario goals to dimension the resources in each group and shift.

\subsubsection{Design and Analysis of Experiments for Resources}

As mentioned, in the previous scenario, the resources were not defined. We performed a DoE design $2^{4}$ to determine the influence of staffing on each shift for TN, EDN1, EDN2, and physicians.

Furthermore, it was defined as an arrangement $2^{3}$ for the porters since they have only three start shift options. The maximum number of staff per hour was considered to define the "level +". Table 6 shows the level of each resource group.

\section{Table 6. DoE variables levels for resources}

The results presented by DoE show that the amount of staff in each shift is statistically significant for at least one of the performance metrics. In this way, we did not remove any input variables. After the analysis and some adjustments, it was determined the ideal number of resources in each group and shift, presented in Table 7. In addition, we proposed a change in the shift of the porters to the same as the other staff.

Table 7. Resource number for shift and group

"Level+" was chosen mostly in the shifts from 9:00 a.m. to 9:00 p.m., because the demand is higher at these times. We decided to maintain the workload of $85 \%$ (average) for nurses and doctors because emergencies may happen. Thereby, these features can meet emergencies without compromising patients already in the ED. Defining the ideal number of resources and executing the model with ten replicates, the results show:

81 - On average, 1504 patients arrived in the model; 
483

484

485

486

487

488

489

490

491

492

493

494

495

496

497

498

499

500

501

502

503

504

505

506

507 - Psychiatrist: a specialist all the time in the unit (avoids the delay that can reach 6 hours);

508 - Neurologist: a specialist in the same shift of the current state (08:00 a.m. - 05:00 p.m.), 509 but allocated directly to the unit (avoiding a delay that can reach 90 minutes);

- All patients make it triage;

- On average, LOS was 511.6 minutes;

- Patients wait about 45.8 minutes to be seen after triage;

- Patients who need to go to SSU wait, on average, 97.1 minutes to be transferred.

The workload was balanced, and the number of treated patients continues the same. However, the LOS average increased around 75 minutes. The waiting time to be attended after triage was, on average, 45.8 minutes, increasing about twice. The waiting time after screening for each CTAS was 6.6 minutes for CTAS I, 13.3 minutes for II, 24.7 minutes for III, 74.0 minutes for IV, and 138.0 for V. Finally, the last improvement proposed is related to the number and scales of the specialist in the unit care.

\subsubsection{Specialists in ED}

When the patients need a medical appointment, they must wait until the specialist arrives at ED, because they are not available in the unit. All the specialists, except the urologist, gynecologist, otolaryngologist, and ophthalmologist, operate all the time. The other specialists work in shifts from 08:00 a.m. to 05:00 p.m. (on average). At other times, the internal medicine covers the cardiologist, nephrologist, and gastroenterologist. Currently, there is only one specialist available for each specialty at each shift, except the Crisis Response, which has two doctors from 08:30 a.m. to 07:30 p.m.

Moreover, it is necessary to consider the response time after calling the specialists. Psychiatrists take between 1 and 6 hours to reach the unit, while neurologists can take 15 to 90 minutes (according to CTAS level), and Crisis Response specialists take about 5 minutes.

Among the 13 specialists, the most requested are psychiatrists, neurologists, and crisis response. Then, these specialists need to stay most of the time in the ED. Therefore, we made some changes in the shifts: 
510

511

512

513 After ten runs, the results are:

514

515

516

517

518

519

520

521

522

523

524

525

526

527

528

529

530

531

532

533

534

535

536

537

538

- All patients make it triage;

\subsection{Confirmation Runs}

- Crisis Response: One expert all the time on the unit rather than two on the predetermined shift (08:30 a.m. - 07:30 p.m.). Although this specialist's response time is relatively short, we chose to allocate it directly to the unit.

- On average, 1496 patients arrived in the model;

- On average, 1441 (96.3\%) patients were completed treated in the simulated period;

- On average, LOS was 450.7 minutes;

- Patients wait about 19.0 minutes to be seen after triage;

- Patients who need to go to SSU wait, on average, 137.2 minutes to be transferred.

One of the actions that blocked continuous patient flow is to wait for the specialist. In this sense, the simulations show that the LOS decreases by about $11.9 \%$. In addition, the waiting time for patients requiring a transfer to SSU is, on average, 42.8 minutes below that requested.

In order to confirm the proposed changes, the model was simulated 30 times and a warm-up from Monday (00:00) to Tuesday (00:00). Data were collected from Tuesday to Tuesday. Table 8 presents the Final Planning (FP) configuration for locations and resources.

\section{Table 8. Number of locations and resources}

According to simulation results, the study recommends two additional beds in the MBA and five additional chairs in the VA. Regarding the resources, it is necessary to hire one TN, one EDN2, four porters, and reduce two physicians. Table 7 lists the shift for each group. It was necessary to dimension the staff, avoiding, when possible, hire them. The number of beds in SSU directly affects patients' LOS. Then, the ideal number is 30 beds, corresponding, on average, 146.4 minutes of waiting for transfer to SSU. About the specialist, a psychiatrist, a neurologist, and a crisis response must stay directly in the unit. With the proposed measures, the patient's LOS decreases by 1752.6 minutes. Table 9 presents the results of the IP and FP scenario.

\section{Table 9. Outputs for IP and FP scenarios}

(Sargent, Goldsman \& Yaacoub 2016) suggest that, for a non-observable system, an objective approach is to compare the results from the developed model with another similar system to 
539 perform the validation. In this sense, we decide to compare the model with another ED that works

540 in the same way to verify the results from the future state. In our model, the mean LOS is 461.2

541 minutes and a standard deviation of 20.7 minutes. In the other ED, the LOS is 472.1 minutes. Then,

542 we carried out a 1-Sample Equivalence test that evaluates if the mean of a population is close

543 enough to a target value, specifying a range to be equivalent. In the test, we can say that the

544 difference between the model's results and benchmarking is not significant, less than 5\% (p-value

$545<0.001)$. In other words, the models are equivalents, and we can affirm that the future state and the

546 results are validated.

547 After the proposed changes, the number of treated patients increased considerably, making their

548 flow continuous during the process (LT principles). In addition, patients are seen as expected after

549 triage, according to the CTAS classification level.

550

\section{5. Conclusions}

552 The presented study aimed to propose an ideal state aligned with LT for a Canadian ED

553 expansion. The purpose was to increase the number of treated patients and reduce LOS, without

554 compromising the quality of services and patient safety. In this way, it determined the optimal

555 number of beds for SSU, BA, MBA, and VA; defined the ideal number of resources; reduced

556 LOS, waiting time after triage phase, and transfer to SSU. Hence, the study used the Modeling

557 and Simulation method proposed by (Montevechi et al. 2010).

558 We built the conceptual model using the IDEF-SIM modeling technique and the input data was

559 obtained through the ED's historical data, registrations from a system, and experts from the

560 hospital. The computer model was built in FlexSim Healthcare ${ }^{\circledR}$ software, and validated it with

561 experts and sensitivity analysis technique. For the experiments, at first, we carried out the DoE to

562 verify the influence of the area expansion (BA, MBA, SSU, and VA) in the chosen metrics. We

563 also used DoE to determine the optimal resource number at each shift and its optimal scale to

564 meet changing demand throughout the day and week. Finally, experiments were performed to

565 reduce patients' waiting time by specialists. Among the evaluated metrics, we chose to prioritize

566 them as follows: (i) weekly treated patients; (ii) LOS; (iii) time for the patient to be attended

567 after triage and (iv) time to transport the patient to SSU.

568 After the analysis, the simulation indicates that the model in its IP scenario cannot meet the

569 demand. For the FP scenario, we observed that DES and LT integrated into the DoE allowed 
570 increasing the number of patients that went through the triage process from $23.1 \%$ to $100.0 \%$.

571 The patient LOS reduced from 2231.8 to 461.2 minutes. The resource workload was balanced

572 according to LT principles. In this way, we got a significant improvement in the process.

573 Regarding the limitations of this study, we found difficulties in executing replicates in the

574 current scenario due to the computational effort required. For this reason, the simulation warm-

575 up was only one day, and the simulation performed for one week (Tuesday to Tuesday). Another

576 significant difficulty was to obtain some data from hospital processes. Even with the use of

577 systems like Meditech ${ }^{\circledR}$, some data are still obtained through expert estimation. According to the

578 literature, this limitation is common in healthcare simulation projects. Finally, for future work,

579 we suggest investigating other resources, e.g., technicians, receptionists, and ward clerk. In

580 addition, the economic viability of different layouts can be assessed for labs and DI.

\section{Acknowledgments}

582 The authors thank the Coordenação de Aperfeiçoamento de Pessoal de Nível Superior (CAPES), 583 the Conselho Nacional de Desenvolvimento Científico e Tecnológico (CNPq), the Fundação de 584 Amparo à Pesquisa do Estado de Minas Gerais FAPEMIG, and Society for Health Systems for

585 supporting this research.

\section{References}

587

588

589

590

591

592

593

594

595

596

597

598

599

600

Al-Araidah O, Boran AM, Wahsheh A. 2012. Reducing Delay in Healthcare Delivery at Outpatients Clinics Using Discrete Event Simulation. International Journal of Simulation Modelling 11(4):185-195.

Arisha A, Rashwan W. 2017. Modeling of Healthcare Systems: Past, Current and Future Trends. In: Proceedings of Winter Simulation Conference. IEEE, 1523-1534. doi:10.1109/WSC.2016.7822203.

Babashov V, Aivas I, Begen MA, Cao JQ, Rodrigues G, D'Souza D, Lock N, Zaric GS. 2017. Reducing Patient Waiting Times for Radiation Therapy and Improving the Treatment Planning Process: A Discrete-Event Simulation Model (Radiation Treatment Planning). Clinical Oncology 29(6):385-391. doi:10.1016/j.clon.2017.01.039.

Banks J, Carson JC, Nelson BL, Nicol MD. 2010. Discrete-Event System Simulation. New Jersey: Pearson Prentice Hall.

Baril C, Gascon V, Vadeboncoeur D. 2019. Discrete event simulation and design of experiments to study ambulatory patient waiting time in an emergency department. Journal of the Operational Research Society 70(12):2019-2038, doi: 10.1080/01605682.2018.1510805

Bem-Tovim D, Filar J, Hakendorf P, Qin S, Thompson P, Ward D. 2016. Hospital Event Simulation Model: 
601

602

603

604

605

606

607

608

609

610

611

612

613

614

615

616

617

618

619

620

621

622

623

624

625

626

627

628

629

630

631

632

633

634

635

636

637

Arrivals to Discharge-Design, Development and Application. Simulation Modelling Practice and Theory 68:80-94.

Bhat S, Gijo EV, Jnanesh NA. 2014. Application of Lean Six Sigma Methodology in the Registration Process of a Hospital. International Journal of Productivity and Performance Management 63(5):613-643. doi:10.1108/IJPPM-11-2013-0191.

Bhattacharjee P, Ray PK. 2018. Schedulling appointments for multiple classes of patients in presence of unscheduled arrivals: Case study of CT department. IISE Transaction on Healthcare Systems Engineering 8(3):181-95. doi: 10.1080/24725579.2018.1442377.

Braislford SC, Hilton NA. 2001. A comparison of discrete event simulation and system dynamics for modelling health care systems. In Proceedings of the 26th meetingof the ORAHS Working Group 2000, 18-39.

Brailsford SC, Eldabi T, Kunc M, Mustafee N, Osorio AF. 2018. Hybrid Simulation Modelling in Operational Research: A State-of-the-Art Review. European Journal of Operational Research 278(3):721-737. doi:10.1016/j.ejor.2018.10.025.

Budgaga W, Malensek M, Pallickara S, Harvey N, Breidt FJ, Pallickara S. 2016. Predictive Analytics Using Statistical, Learning, and Ensemble Methods to Support Real-Time Exploration of Discrete Event Simulations. Future Generation Computer Systems 56:360-374.

Cheng R, Macal C, Nelson B, Rabe M, Currie C, Fowler J, Lee LH. 2017. Simulation: The Past 10 Years and the next 10 Years. In: Proceedings of Winter Simulation Conference, 2180-2192.

D’Andreamatteo A, Ianni L, Lega F, Sargiacomo M. 2015. Lean in Healthcare: A Comprehensive Review. Health Policy 119(9):1197-1209. doi:10.1016/j.healthpol.2015.02.002.

Dengiz, B, Belgin O. 2014. Simulation Optimization of a Multi-Stage Multi-Product Paint Shop Line with Response Surface Methodology. Simulation: Transactions of the Society for Modeling and Simulation International, 110 .

Doğan NÖ, Unutulmaz O. 2016. Lean Production in Healthcare: A Simulation-Based Value Stream Mapping in the Physical Therapy and Rehabilitation Department of a Public Hospital. Total Quality Management and Business Excellence 27(1-2):64-80. doi:10.1080/14783363.2014.945312.

Gaba, DM. 2004. The Future Vision of Simulation in Health Care. Quality and Safety in Health Care 13:2-11. doi:10.1136/qshc.2004.009878.

Graban M. 2016. Lean Hospitals: Improving Quality, Patient Safety, and Employee Engagement. New York: Productivity Press.

Gul M, Guneri AF, Gunal MM. 2016. Emergency department network under disaster conditions: The case of possible major Istanbul earthquake. Journal of the Operational Research Society, doi: 10.1080/01605682.2019.1582588

Haddad MG, Zouein PP, Salem J, Otayek R. 2016. Case Study of Lean in Hospital Admissions to Inspire Culture Change. Engineering Management Journal 28(4):209-223. doi:10.1080/10429247.2016.1234896.

Harrell C, Ghosh BK, Bowden R. 2012. Simulation Using ProModel. New York: McGraw-Hill Education.

Hussein NA, Abdelmaguid TF, Tawfik BS, Ahmed NGS. 2017. Mitigating Overcrowding in Emergency

Peer] Comput. Sci. reviewing PDF | (CS-2019:08:40076:3:1:NEW 25 Jun 2020) 

15:1-12. doi:10.1016/j.orhc.2017.06.003.

640

641

642

643

644

645

646

647

648

649

650

651

652

653

654

655

656

657

658

659

660

661

662

663

664

665

666

667

668

669

670

671

672

673

674

Kimsey DB. 2010. Lean Methodology in Health Care. AORN 92(1):53-60. doi:10.1016/j.chest.2018.06.005.

Kleijnen JPC. 1995. Verification and validation of simulations models. European Journal of Operational Research 82(1).

Laganga LR. 2011. Lean Service Operations: Reflections and New Directions for Capacity Expansion in Outpatient Clinics. Journal of Operations Management 29(5):422-433. doi:10.1016/j.jom.2010.12.005.

Lopes HS, Lima RS, Leal F, Nelson AC. 2017 Scenario analysis of Brazilian soybean exports via discrete event simulation applied to soybean transportation: The case of Mato Grosso State. Research in Transportation Business \& Management 25:66-75.

Montevechi JAB, Leal F, Pinho AF, Costa RFS, Oliveira MLM, Silva ALF. 2010. Conceptual Modeling in Simulation Projects by Mean Adapted IDEF: An Application in a Brazilian Tech Company. In: Proceedings of Winter Simulation Conference 1624-1635.

Montevechi JAB, Pinho AFP, Leal F, Marins FAS. 2007. Application of Design of Experiments on the Simulation of a Process in an Automotive Industry. In: Proceddings of Winter Simulation Conference.

Montgomery DC. 2017. Design and Analysis of Experiments. John Wiley \& Sons Inc.

Montgomery DC, Runger GC. 2018. Applied Statistics and Probability for Engineers. New York: John Wiley \& Sons Inc.

Negahban A, Yilmaz L. 2014. Agent-Based Simulation Applications in Marketing Research: An Integrated Review. Journal of Simulation 8(2): 129-142.

Papadopoulos T, Radnor Z, Merali Y. 2011. The Role of Actor Associations in Understanding the Implementation of Lean Thinking in Healthcare. International Journal of Operations and Production Management 31(2):167191. doi:10.1108/01443571111104755.

Pereira TF, Montevechi JAB, Miranda RC, Friend JD. 2015. Integrating Soft Systems Methodology to Aid Simulation Conceptual Modeling. International Transactions in Operational Research 22(2):265-285. doi:10.1111/itor.12133.

Peixoto TA, Assis RJJ, Matias IO, Silva FF, Tavares ER. 2017. Ururau: A free and open-source discrete event simulation software. Journal of Simulation 11(4):303-32.

Pinto LR, Campos FCC, Perpetuo IHO, Ribeiro YCNMB. 2015. Analisys of Hospital Bed Capacity via Queuing Theory and Simulation. In: Proceedings of Winter Simulation Conference 1281-1292.

Pitt M. 2008. 'Simulation for Strategic Planning in Health Care -"The State of the Art"”. http://www.institute.nhs.uk/images//\%0Adocuments/BuildingCapability/ScenarioGenerator/state-of-theart.pdf.

Pongjetanapong K, Walker C, O'Sullivan M, Lovell-Smith M, Furian N. 2019. Exploring Trade-Offs between Staffing Levels and Turnaround Time in a Pathology Laboratory Using Discrete Event Simulation. International Journal of Health Planning and Management 34(2):1119-1134. doi:10.1002/hpm.2748.

Rau CL, Tsai PF, Liang SF, Tan JC, Syu HC, Jheng YL, Ciou TS, Jaw FS. 2013. Using Discrete-Event

Peerj Comput. Sci. reviewing PDF | (CS-2019:08:40076:3:1:NEW 25 Jun 2020) 
675

676

677

678

679

680

681

682

683

684

685

686

687

688

689

690

691

692

693

694

695

696

697

698

699

700

701

702

703

704

705

706

707

708

709

710

Simulation in Strategic Capacity Planning for an Outpatient Physical Therapy Service. Health Care Management Science 16(4):352-365. doi:10.1007/s10729-013-9234-2.

Reynolds M, Vasilakis C, McLeod M, Barber N, Mounsey A, Newton S, Jacklin A, Franklin BD. 2011. Using Discrete Event Simulation to Design a More Efficient Hospital Pharmacy for Outpatients. Health Care Management Science 14(3):223-236. doi:10.1007/s10729-011-9151-1.

Robinson S, Radnor ZJ, Burgess N, Worthington C. 2012. SimLean: Utilising Simulation in the Implementation of Lean in Healthcare. European Journal of Operational Research 219(1):188-197. doi:10.1016/j.ejor.2011.12.029.

Robinson S, Worthington C, Burgess N, Radnor ZJ. 2014. Facilitated Modelling with Discrete-Event Simulation: Reality or Myth? European Journal of Operational Research 234(1):231-240. doi:10.1016/j.ejor.2012.12.024.

Salam MA, Khan SA. 2016. Value Creation through Lean Management: A Case Study of Healthcare Service Operations. International Journal of Services and Operations Management 25(3):275. doi:10.1504/IJSOM.2016.079513.

Sargent RG. 2013. Verification and Validation of Simulation Models. Journal of Simulation 7(1):12-24. doi:10.1057/jos.2012.20.

Sargent RG., Goldsman DM, Yaacoub T. 2016. A Tutorial on the Operational Validation of Simulation Model. In: Proceedings of Winter Simulation Conference.

Shim SJ, Kumar A. 2010. Simulation for Emergency Care Process Reengineering in Hospitals. Business Process Management Journal 16(5):795-805. doi:10.1108/14637151011076476.

Swick M, Doulaveris P, Timothy B, Womack D. 2012. Application of Simulation Technology to Enhance the Role of the Professional Nurse. Journal of Nursing Administration 42(2):95-102. doi:10.1097/NNA.0b013e3182433706.

Tako AA, Robinson S. 2015. Is simulation in health different? Journal of the Operational Research Society 66(4):602-614. doi:10.1057/jors.2014.25.

Teichgräber UK, Bucourt MD. 2012. Applying Value Stream Mapping Techniques to Eliminate Non-Value-Added Waste for the Procurement of Endovascular Stents. European Journal of Radiology 81(1):47-52. doi:10.1016/j.ejrad.2010.12.045.

Toussaint JS, Berry LL. 2013. The Promise of Lean in Health Care. Mayo Clinic Proceedings 88(1):74-82. doi:10.1016/j.mayocp.2012.07.025.

Uriarte AG, Zúñiga ER, Moris MU, Ng AHC. 2017. How Can Decision Makers Be Supported in the Improvement of an Emergency Department? A Simulation, Optimization and Data Mining Approach. Operations Research for Health Care 15:102-122. doi:10.1016/j.orhc.2017.10.003.

Womack JP, Jones DT, Roos D. 1990. The Machine That Changed the World. New York: Free Press. World Bank. 2019. 'World Development Indicators'. https://data.worldbank.org/indicator/SH.XPD.CHEX.GD.ZS. Zhou QS, Olsen TL. 2018. Rotating the Medical Supplies for Emergency Response: A Simulation Based Approach. International Journal of Production Economics 196:1-11. doi:10.1016/j.ijpe.2017.11.010.

Peer] Comput. Sci. reviewing PDF | (CS-2019:08:40076:3:1:NEW 25 Jun 2020) 


\section{Table $\mathbf{1}$ (on next page)}

Table 1. Patient's category and specialist 


\begin{tabular}{ccc}
\hline Treatment Category & Specialist & Proportion \\
\hline General/Minor issues (GMI) & - & $17.7 \%$ \\
Respiratory (RE) & Respiratory Therapist & $14.6 \%$ \\
Gastroenterology (GA) & Gastroenterologist & $11.9 \%$ \\
Orthopedic (OR) & Orthopedist & $10.3 \%$ \\
Cardiology (CA) & Cardiologist & $9.7 \%$ \\
Dermatology (DE) & Dermatologist & $8.3 \%$ \\
Genitourinary (GE) & Urologist and Nephrologist & $6.1 \%$ \\
Ear, nose, and throat (ENT) & Otolaryngologist & $4.9 \%$ \\
Mental Health (MH) & Crisis and Psychologist & $4.3 \%$ \\
Neurologic (NE) & Neurologist & $4.2 \%$ \\
Ambulatory Return Visit (ARV) & - & $4.0 \%$ \\
Ophthalmology (OP) & Ophthalmologist & $1.8 \%$ \\
Gynecology (GY) & Gynecologist & $1.1 \%$ \\
Substance Misuse (SM) & Crisis and Psychologist & $0.9 \%$ \\
\hline
\end{tabular}

1 


\section{Table 2 (on next page)}

Table 2. Processing time and required staff 


\begin{tabular}{|c|c|c|c|c|c|c|c|}
\hline \multirow[b]{2}{*}{ Task } & \multirow[b]{2}{*}{$\begin{array}{l}\text { Process Time } \\
\text { (min) }\end{array}$} & \multicolumn{6}{|c|}{ Staff Required } \\
\hline & & 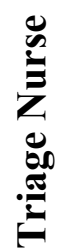 & 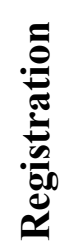 & 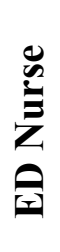 & 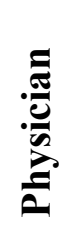 & $\frac{\Xi}{\dot{E}}$ & 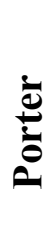 \\
\hline Triage & $\mathrm{T}(4,7,10)$ & $\mathrm{x}$ & & & & & \\
\hline Escort to Bed & $\mathrm{T}(0.5,1,2)$ & & & $\mathrm{x}$ & & & \\
\hline Register Patient & 3 & & $\mathrm{x}$ & & & & \\
\hline Nurse Assessment & $\begin{array}{l}\text { CTASIV/V: } 5 \text {; } \\
\text { CTASIII: } 10 \text {; } \\
\text { CTASII: } 15\end{array}$ & & & $\mathrm{x}$ & & & \\
\hline Physician Assessment & $\mathrm{T}(7,12,15)$ & & & & $\mathrm{x}$ & & \\
\hline Write Patient Orders & $\mathrm{T}(2,4,5)$ & & & & $\mathrm{x}$ & & \\
\hline Initiate DI/Lab & $\mathrm{T}(2,2.5,3)$ & & & & & $\mathrm{x}$ & \\
\hline Prepare Patient for DI & 3 & & & $\mathrm{x}$ & & & \\
\hline Receive/Add Tests to Chart & 1 & & & $\mathrm{x}$ & & $\mathrm{x}$ & \\
\hline Review Tests (Nurse) & 1 & & & $\mathrm{x}$ & & & \\
\hline Review Tests (Physician) & 2 & & & & $\mathrm{x}$ & & \\
\hline Take Specimen & $\mathrm{T}(4,6,15)$ & & & $\mathrm{x}$ & & & \\
\hline Medical Procedure* & $\mathrm{T}(15,20,60)$ & & & $\mathrm{x}$ & $\mathrm{x}$ & & \\
\hline Initiate Consult & 2 & & & & & $\mathrm{x}$ & \\
\hline Arrange Consultant & 2 & & & & & $\mathrm{x}$ & \\
\hline Discuss with Specialist & 3 & & & & $\mathrm{x}$ & & \\
\hline Make Disposition & $20 \%-30 ; 80 \%-3$ & & & & $\mathrm{x}$ & & \\
\hline Admission Form & 2 & & & $\mathrm{x}$ & & & \\
\hline Determine Care Plan & $\mathrm{T}(7,10,12)$ & & & & $\mathrm{x}$ & & \\
\hline Contact Specialist & 5 & & & & $\mathrm{x}$ & & \\
\hline Transport Patient to SSU (I and II)* & $\mathrm{T}(15,20,25)$ & & & $\mathrm{x}$ & & & $\mathrm{x}$ \\
\hline Care Plan and Final Orders & $\mathrm{T}(2,4,10)$ & & & & $\mathrm{x}$ & & \\
\hline Give Instruction & $\mathrm{T}(2,5,12)$ & & & $\mathrm{x}$ & & & \\
\hline Prepare Patient & $\mathrm{T}(1,2,4)$ & & & $\mathrm{x}$ & & & \\
\hline Shift Change Written/Verbal & 5 & & & & $\mathrm{x}$ & & \\
\hline EHS Call & 1 & $\mathrm{x}$ & & $\mathrm{x}$ & & & \\
\hline EHS Triage & $\mathrm{T}(4,7,10)$ & $\mathrm{x}$ & & $\mathrm{x}$ & & & \\
\hline Prepare Room for Next Patient & 1 & & & $\mathrm{x}$ & & & \\
\hline Huddle* & 10 & $x$ & $\mathrm{X}$ & $\mathrm{x}$ & $\mathrm{x}$ & $\mathrm{x}$ & \\
\hline
\end{tabular}

*denotes a task which requires all staff indicated (x). 


\section{Table 3(on next page)}

Table 3. Exam probability for each CTAS level 


\begin{tabular}{|c|c|c|c|c|c|c|c|c|c|c|c|c|c|c|}
\hline \multirow[b]{2}{*}{ Exam } & \multirow[b]{2}{*}{ CTAS } & \multicolumn{13}{|c|}{ Treatment Category } \\
\hline & & GMI & $\mathbf{R E}$ & GA & OR & CA & DE & GE & ENT & MH & NE & $\mathbf{O P}$ & GY & SM \\
\hline \multirow{3}{*}{ CT } & I and II & $1 \%$ & $\mathrm{x}$ & $\checkmark$ & $50 \%$ & $\mathrm{x}$ & $\mathrm{x}$ & $\checkmark$ & $\checkmark$ & $\mathrm{x}$ & $\checkmark$ & $50 \%$ & $\mathrm{x}$ & $\mathrm{x}$ \\
\hline & III & $1 \%$ & $\mathrm{x}$ & $50 \%$ & $10 \%$ & $\mathrm{x}$ & $\mathrm{x}$ & $50 \%$ & $\mathrm{x}$ & $\mathrm{x}$ & $\mathrm{x}$ & $\mathrm{x}$ & $\mathrm{x}$ & $\mathrm{x}$ \\
\hline & IV and $\mathrm{V}$ & $1 \%$ & $\mathrm{x}$ & $\mathrm{x}$ & $\mathrm{x}$ & $\mathrm{x}$ & $\mathrm{x}$ & $\mathrm{x}$ & $\mathrm{x}$ & $\mathrm{x}$ & $\mathrm{x}$ & $\mathrm{x}$ & $\mathrm{x}$ & $\mathrm{x}$ \\
\hline \multirow{3}{*}{ ECHO } & I and II & $\mathrm{x}$ & $\mathrm{x}$ & $\mathrm{x}$ & $\mathrm{x}$ & $10 \%$ & $\mathrm{x}$ & $\mathrm{x}$ & $\mathrm{x}$ & $\mathrm{x}$ & $\mathrm{x}$ & $\mathrm{x}$ & $\mathrm{x}$ & $\mathrm{x}$ \\
\hline & III & $\mathrm{x}$ & $\mathrm{x}$ & $\mathrm{x}$ & $\mathrm{x}$ & $\mathrm{x}$ & $\mathrm{x}$ & $\mathrm{x}$ & $\mathrm{x}$ & $\mathrm{x}$ & $\mathrm{x}$ & $\mathrm{x}$ & $\mathrm{x}$ & $\mathrm{x}$ \\
\hline & IV and V & $\mathrm{x}$ & $\mathrm{X}$ & $\mathrm{x}$ & $\mathrm{x}$ & $\mathrm{x}$ & $\mathrm{x}$ & $\mathrm{x}$ & $\mathrm{x}$ & $\mathrm{x}$ & $\mathrm{x}$ & $\mathrm{x}$ & $\mathrm{x}$ & $\mathrm{x}$ \\
\hline \multirow{3}{*}{ EKG } & I and II & $\mathrm{x}$ & $\checkmark$ & $\mathrm{x}$ & $75 \%$ & $\checkmark$ & $25 \%$ & $\mathrm{x}$ & $\mathrm{x}$ & $\mathrm{x}$ & $\mathrm{x}$ & $\mathrm{x}$ & $\mathrm{x}$ & $\mathrm{x}$ \\
\hline & III & $\mathrm{x}$ & $\mathrm{x}$ & $\mathrm{x}$ & $75 \%$ & $\checkmark$ & $\mathrm{X}$ & $\mathrm{x}$ & $\mathrm{x}$ & $\mathrm{x}$ & $\mathrm{x}$ & $\mathrm{x}$ & $\mathrm{x}$ & $\mathrm{x}$ \\
\hline & IV and V & $\mathrm{x}$ & $\mathrm{x}$ & $\mathrm{x}$ & $\mathrm{x}$ & $\checkmark$ & $\mathrm{x}$ & $\mathrm{x}$ & $\mathrm{x}$ & $\mathrm{x}$ & $\mathrm{x}$ & $\mathrm{x}$ & $\mathrm{x}$ & $\mathrm{x}$ \\
\hline \multirow{3}{*}{ US } & I and II & $1 \%$ & $\mathrm{x}$ & $\checkmark$ & $\mathrm{x}$ & $\mathrm{x}$ & $\mathrm{x}$ & $\checkmark$ & $\mathrm{x}$ & $\mathrm{x}$ & $\mathrm{x}$ & $\mathrm{x}$ & $\checkmark$ & $\mathrm{x}$ \\
\hline & III & $1 \%$ & $\mathrm{x}$ & $50 \%$ & $\mathrm{x}$ & $\mathrm{x}$ & $\mathrm{x}$ & $50 \%$ & $\mathrm{x}$ & $\mathrm{x}$ & $\mathrm{x}$ & $\mathrm{x}$ & $\checkmark$ & $\mathrm{x}$ \\
\hline & IV and V & $1 \%$ & $\mathrm{x}$ & $\mathrm{x}$ & $\mathrm{x}$ & $\mathrm{x}$ & $\mathrm{x}$ & $\mathrm{x}$ & $\mathrm{x}$ & $\mathrm{x}$ & $\mathrm{x}$ & $\mathrm{x}$ & $\mathrm{x}$ & $\mathrm{x}$ \\
\hline \multirow{3}{*}{ XR } & I and II & $50 \%$ & $\checkmark$ & $\checkmark$ & $\checkmark$ & $\checkmark$ & $25 \%$ & $\checkmark$ & $\checkmark$ & $\mathrm{x}$ & $\checkmark$ & $25 \%$ & $\mathrm{x}$ & $\mathrm{x}$ \\
\hline & III & $50 \%$ & $\checkmark$ & $50 \%$ & $\checkmark$ & $75 \%$ & $\mathrm{x}$ & $50 \%$ & $25 \%$ & $\mathrm{x}$ & $\mathrm{x}$ & $\mathrm{X}$ & $\mathrm{x}$ & $\mathrm{x}$ \\
\hline & IV and V & $50 \%$ & $25 \%$ & $\mathrm{x}$ & $50 \%$ & $75 \%$ & $\mathrm{x}$ & $\mathrm{x}$ & $\mathrm{x}$ & $\mathrm{x}$ & $25 \%$ & $\mathrm{x}$ & $\mathrm{x}$ & $\mathrm{x}$ \\
\hline \multirow{3}{*}{ BW } & I and II & $50 \%$ & $\checkmark$ & $\checkmark$ & $\checkmark$ & $\checkmark$ & $75 \%$ & $\checkmark$ & $\checkmark$ & $\checkmark$ & $\checkmark$ & $\checkmark$ & $\checkmark$ & $\checkmark$ \\
\hline & III & $50 \%$ & $\checkmark$ & $\checkmark$ & $\checkmark$ & $\checkmark$ & $25 \%$ & $\checkmark$ & $25 \%$ & $\checkmark$ & $\checkmark$ & $\mathrm{x}$ & $\checkmark$ & $\checkmark$ \\
\hline & IV and $\mathrm{V}$ & $50 \%$ & $\mathrm{x}$ & $\mathrm{X}$ & $\mathrm{x}$ & $25 \%$ & $\mathrm{X}$ & $\mathrm{x}$ & $\mathrm{x}$ & $50 \%$ & $10 \%$ & $\mathrm{x}$ & $50 \%$ & $75 \%$ \\
\hline \multirow{3}{*}{ SP } & I and II & $\mathrm{X}$ & $\checkmark$ & $50 \%$ & $25 \%$ & $\mathrm{x}$ & $25 \%$ & $\checkmark$ & $25 \%$ & $\checkmark$ & $\checkmark$ & $\mathrm{x}$ & $\checkmark$ & $\checkmark$ \\
\hline & III & $\mathrm{x}$ & $75 \%$ & $50 \%$ & $10 \%$ & $\mathrm{x}$ & $25 \%$ & $\checkmark$ & $50 \%$ & $\checkmark$ & $50 \%$ & $\mathrm{x}$ & $\checkmark$ & $\checkmark$ \\
\hline & IV and $\mathrm{V}$ & $\mathrm{x}$ & $25 \%$ & $\mathrm{x}$ & $\mathrm{x}$ & $\mathrm{x}$ & $\mathrm{x}$ & $\checkmark$ & $\mathrm{x}$ & $50 \%$ & $\mathrm{x}$ & $\mathrm{x}$ & $50 \%$ & $75 \%$ \\
\hline
\end{tabular}




\section{Table 4 (on next page)}

Table 4. Specialist probability appointment for each CTAS level and data set 


\begin{tabular}{|c|c|c|c|c|c|c|c|}
\hline \multirow{2}{*}{$\begin{array}{l}\text { Treatment } \\
\text { Category }\end{array}$} & \multirow{2}{*}{ Consult 1} & \multicolumn{2}{|c|}{ CTAS I and II } & \multicolumn{2}{|c|}{ CTAS III } & \multicolumn{2}{|c|}{ CTAS IV and V } \\
\hline & & C1 & Time (min) & C1 & Time (min) & C1 & Time (min) \\
\hline $\mathbf{R E}$ & $\begin{array}{c}\text { Respiratory } \\
\text { Therapist }\end{array}$ & $75 \%$ & 60 & $10 \%$ & 15 & $\mathrm{x}$ & $\mathrm{x}$ \\
\hline GA & Gastroenterologist & $\checkmark$ & $\mathrm{T}(15,22,30)$ & $25 \%$ & $\mathrm{~T}(15,22,30)$ & $\mathrm{x}$ & $\mathrm{T}(15,22,30)$ \\
\hline OR & Orthopedist & $\checkmark$ & 10 & $\checkmark$ & 5 & $50 \%$ & 3 \\
\hline CA & Cardiologist & $\checkmark$ & $\mathrm{T}(30,45,60)$ & $50 \%$ & $\mathrm{~T}(30,45,60)$ & $10 \%$ & $\mathrm{~T}(30,45,60)$ \\
\hline DE & Dermatologist & $25 \%$ & $\mathrm{~T}(30,45,60)$ & $10 \%$ & $\mathrm{~T}(30,45,60)$ & $\mathrm{x}$ & $\mathrm{x}$ \\
\hline GE & Urologist & $\checkmark$ & $\mathrm{T}(15,22,30)$ & $\checkmark$ & $\mathrm{T}(15,22,30)$ & $\mathrm{x}$ & $\mathrm{x}$ \\
\hline ENT & Otolaryngologist & $\checkmark$ & 60 & $50 \%$ & 20 & $\mathrm{x}$ & $\mathrm{x}$ \\
\hline MH & Crisis Response & $\checkmark$ & $\mathrm{T}(60,75,90)$ & $\checkmark$ & $\mathrm{T}(60,75,90)$ & $\checkmark$ & $\mathrm{T}(60,75,90)$ \\
\hline $\mathbf{N E}$ & Neurologist & $\checkmark$ & 60 & $\checkmark$ & 60 & $\mathrm{x}$ & $\mathrm{x}$ \\
\hline OP & Ophthalmologist & $10 \%$ & $\mathrm{~T}(30,45,60)$ & $5 \%$ & $\mathrm{~T}(30,45,60)$ & $\mathrm{x}$ & $\mathrm{x}$ \\
\hline GY & Gynecologist & $\checkmark$ & $\mathrm{T}(15,22,30)$ & $\checkmark$ & $\mathrm{T}(15,22,30)$ & $\mathrm{x}$ & $\mathrm{x}$ \\
\hline SM & Crisis & $\checkmark$ & $\mathrm{T}(60,75,90)$ & $\checkmark$ & $\mathrm{T}(60,75,90)$ & $\checkmark$ & $\mathrm{T}(60,75,90)$ \\
\hline \multirow{2}{*}{$\begin{array}{l}\text { Treatment } \\
\text { Category } \\
\end{array}$} & \multirow{2}{*}{ Consult 2} & \multicolumn{2}{|c|}{ CTAS I and II } & \multicolumn{2}{|c|}{ CTAS III } & \multicolumn{2}{|c|}{ CTAS IV and V } \\
\hline & & $\mathrm{C2}$ & Time (m) & $\mathrm{C2}$ & Time (m) & $\mathrm{C2}$ & Time (m) \\
\hline GE & Nephrologist & $50 \%$ & $\mathrm{~T}(10,15,20)$ & $25 \%$ & $\mathrm{~T}(30,45,60)$ & $\mathrm{x}$ & $\mathrm{x}$ \\
\hline МH & Psychologist & $\checkmark$ & $\mathrm{T}(60,75,90)$ & $75 \%$ & $\mathrm{~T}(60,75,90)$ & $25 \%$ & $\mathrm{~T}(60,75,90)$ \\
\hline SM & Psychologist & $\checkmark$ & $\mathrm{T}(60,75,90)$ & $50 \%$ & $\mathrm{~T}(60,75,90)$ & $25 \%$ & $\mathrm{~T}(60,75,90)$ \\
\hline
\end{tabular}




\section{Table 5 (on next page)}

Table 5. Variables related to locations and DoE parameters 


\begin{tabular}{cccccc}
\hline \multirow{2}{*}{ Variable } & \multicolumn{2}{c}{ Number of location } & \multicolumn{3}{c}{ DoE Parameters } \\
\cline { 2 - 6 } & IP & Ideal & Low Level & Centre Point & High Level \\
\hline SSU & 10 & 30 & 10 & 20 & 30 \\
BA & 45 & 49 & 45 & 49 & 53 \\
MBA & 3 & 4 & 3 & 4 & 5 \\
VA & 10 & 13 & 10 & 13 & 15 \\
\hline
\end{tabular}

1 


\section{Table 6(on next page)}

Table 6. DoE variables levels for resources 


\begin{tabular}{|c|c|c|c|c|c|}
\hline & \multicolumn{4}{|c|}{ Shift } & \multirow[b]{2}{*}{ Resource } \\
\hline & $\begin{array}{l}\text { 07:00 a.m. } \\
\text { 07:00 p.m. }\end{array}$ & $\begin{array}{l}\text { 09:00 a.m. } \\
\text { 09:00 p.m. }\end{array}$ & $\begin{array}{l}\text { 11:00 a.m. } \\
\text { 11:00 p.m. }\end{array}$ & $\begin{array}{l}\text { 07:00 p.m. } \\
\text { 07:00 a.m. }\end{array}$ & \\
\hline Level- & 1 & 0 & 1 & 1 & \multirow{2}{*}{$\mathbf{T N}$} \\
\hline Level+ & 2 & 1 & 2 & 2 & \\
\hline Level- & 4 & 0 & 1 & 4 & \multirow{2}{*}{ EDN1 } \\
\hline Level+ & 8 & 2 & 2 & 8 & \\
\hline Level- & 3 & 1 & 1 & 3 & \multirow{2}{*}{ EDN2 } \\
\hline Level+ & 6 & 2 & 2 & 6 & \\
\hline Level- & 3 & 0 & 2 & 3 & \multirow{2}{*}{ Physician } \\
\hline Level+ & 6 & 2 & 1 & 6 & \\
\hline & $\begin{array}{l}\text { 07:00 a.m. } \\
\text { 07:00 p.m. }\end{array}$ & $\begin{array}{l}\text { 10:00 a.m. } \\
\text { 06:00 p.m. }\end{array}$ & $\begin{array}{l}\text { 07:00 a.m. } \\
\text { 07:00 p.m. }\end{array}$ & & \\
\hline Level- & 2 & 2 & 2 & & \multirow{2}{*}{ Porter } \\
\hline Level+ & 3 & 3 & 3 & & \\
\hline
\end{tabular}




\section{Table 7 (on next page)}

Table 7. Resource number for shift and group 


\begin{tabular}{ccccc}
\hline & \multicolumn{4}{c}{ Shift } \\
\cline { 2 - 5 } Staff & $\mathbf{0 7 : 0 0}$ a.m. & $\mathbf{0 9 : 0 0}$ a.m. & $\mathbf{1 1 : 0 0}$ a.m. & $\mathbf{0 7 : 0 0}$ p.m. \\
& $\mathbf{0 7 : 0 0}$ p.m. & $\mathbf{0 9 : 0 0}$ p.m. & $\mathbf{1 1 : 0 0}$ p.m. & $\mathbf{0 7 : 0 0}$ a.m. \\
\hline TN & 1 & 0 & 1 & 2 \\
ED1 & 4 & 2 & 0 & 3 \\
ED2 & 3 & 1 & 2 & 3 \\
Physician & 3 & 2 & 2 & 3 \\
Porter & 3 & 1 & 0 & 3 \\
\hline
\end{tabular}

1 


\section{Table 8 (on next page)}

Table 8. Number of locations and resources 


\begin{tabular}{cccccc}
\hline Local & IP & FP & Resource & IP & FP \\
\hline BA & 45 & 45 & TN & 3 & 4 \\
MBA & 3 & 5 & EDN1 & 9 & 9 \\
SSU & 10 & 30 & EDN2 & 8 & 9 \\
VA & 10 & 15 & Physicians & 12 & 10 \\
& & & Porters & 3 & 7 \\
\hline
\end{tabular}

1 


\section{Table 9 (on next page)}

Table 9. Outputs for IP and FP scenario 


\begin{tabular}{|c|c|c|c|c|c|c|}
\hline & \multirow{2}{*}{ Metrics (min) } & \multicolumn{2}{|c|}{ Initial Planning } & \multicolumn{2}{|c|}{ Final Planning } & \multirow{2}{*}{$\begin{array}{c}\text { Rate } \\
\text { (mean) }\end{array}$} \\
\hline & & Mean & Confidence Interval & Mean & Confidence Interval & \\
\hline \multirow{4}{*}{ Patients } & Input & 1504 & - & 1506 & - & - \\
\hline & Output & 258 & - & 1444 & - & $560 \%$ \\
\hline & Treated $(\%)$ & 17.2 & - & 95.7 & - & $556 \%$ \\
\hline & Triage (\%) & 23.1 & - & 100.0 & - & $433 \%$ \\
\hline \multirow{6}{*}{ LOS } & Average & 2213.7 & $(2131.8-2295.6)$ & 461.2 & $(453.7-468.7)$ & $-79 \%$ \\
\hline & CTAS I & 2809.9 & $(1381.3-4750.1)$ & 1072.2 & $(787.6-1356.8)$ & $-62 \%$ \\
\hline & CTAS II & 3077.2 & $(2778.8-3375.6)$ & 918.2 & $(880.9-955.5)$ & $70 \%$ \\
\hline & CTAS III & 2219.3 & $(2051.2-2387.5)$ & 452.7 & $(438.8-466.6)$ & $-80 \%$ \\
\hline & CTAS IV & 1746.2 & $(1585.5-1907.9)$ & 252.8 & $(246.1-259.5)$ & $-86 \%$ \\
\hline & CTAS V & 1500.8 & $(903.5-2091.0)$ & 299.9 & $(275.4-324.4)$ & $-80 \%$ \\
\hline \multirow{7}{*}{$\begin{array}{l}\text { Triage } \\
\text { to Bed }\end{array}$} & Average & 404.3 & $(369.7-439.0)$ & 20.8 & $(19.8-21.8)$ & $-95 \%$ \\
\hline & CTAS I & 25.9 & $(4.2-47.5)$ & 11.2 & $(6.1-17.4)$ & $-57 \%$ \\
\hline & CTAS II & 164.6 & $(121.6-207.7)$ & 10.4 & $(6.1-16.3)$ & $-94 \%$ \\
\hline & CTAS III & 332.2 & $(275.2-389.3)$ & 13.7 & $(12.9-14.5)$ & $-96 \%$ \\
\hline & CTAS IV & 649.7 & $(559.9-739.5)$ & 26.9 & $(25.2-28.7)$ & $-96 \%$ \\
\hline & CTAS V & 419.5 & $(131.0-707.9)$ & 82.1 & $(64.6-99.7)$ & $-80 \%$ \\
\hline & Bed to SSU & 367.4 & $(253.1-481.7)$ & 146.4 & $(133.8-159.0)$ & $-60 \%$ \\
\hline
\end{tabular}


Figure 1

Figure 1. Conceptual Modeling
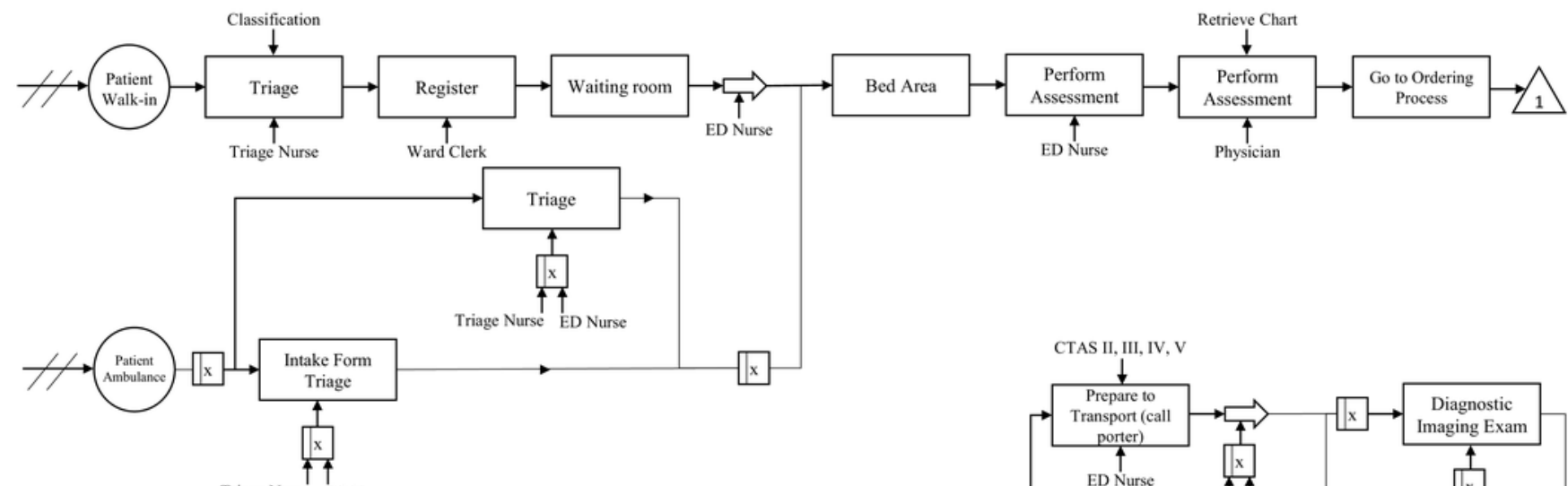

Triage Nurse ED Nurse
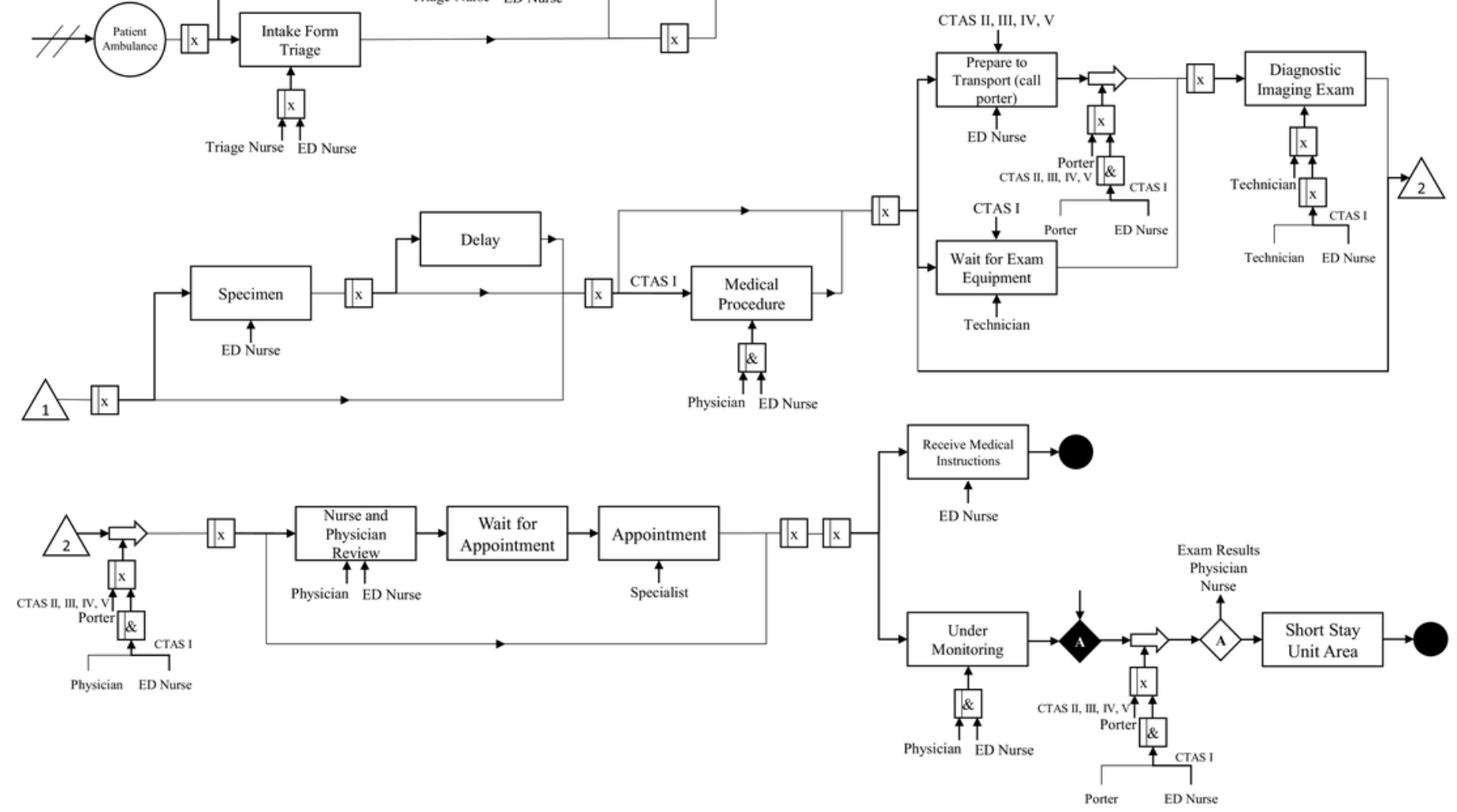
Figure 2

Figure 2. Arrival rate for each patient CTAS level

(A) CTAS level I patient arrivals during the week. (B) CTAS level II patient arrivals during the week. (C) CTAS level III patient arrivals during the week. (D) CTAS level IV patient arrivals during the week. (E) CTAS level V patient arrivals during the week.

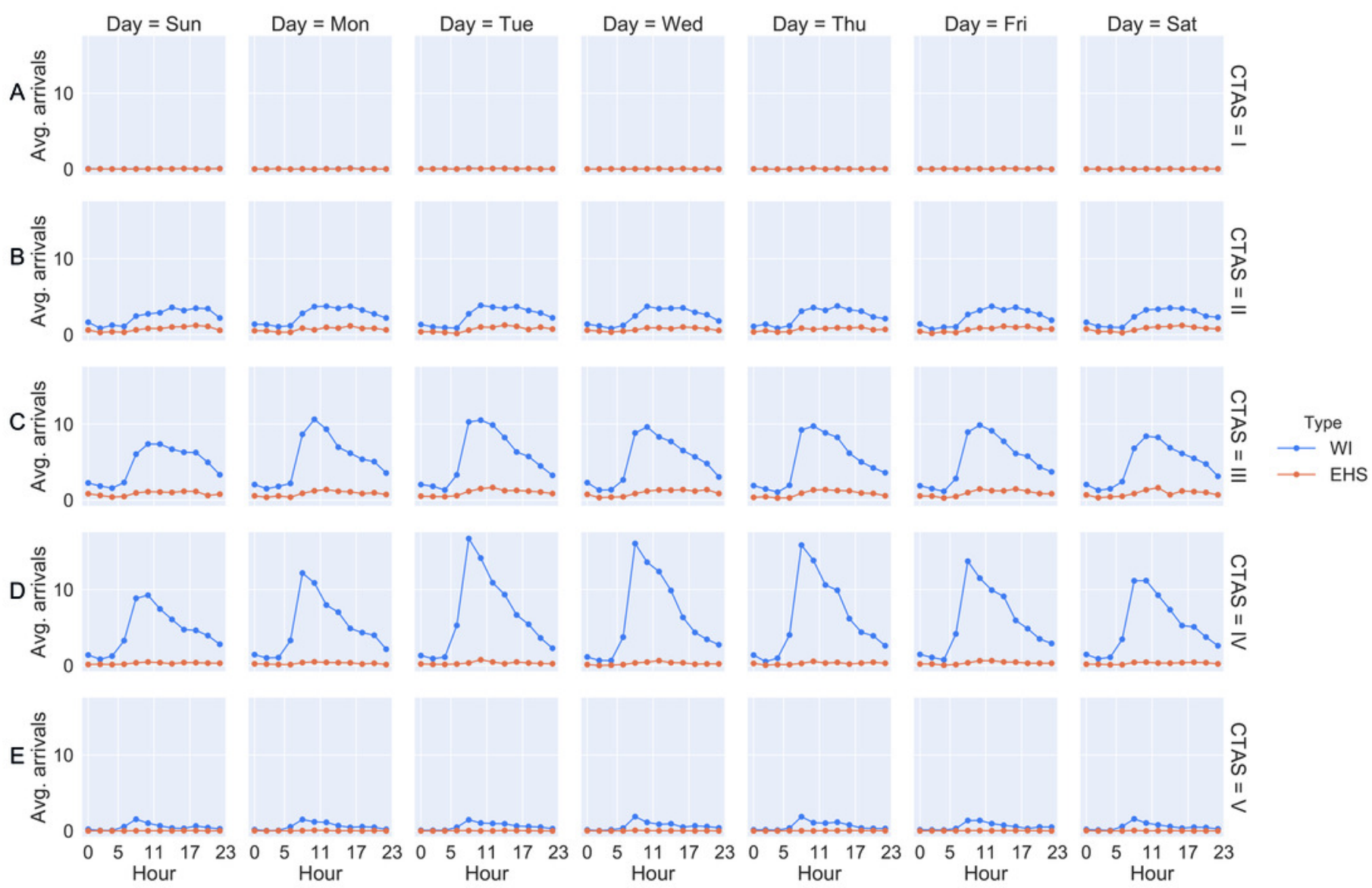




\section{Figure 3}

Figure 3. Computer model screen in the FP scenario

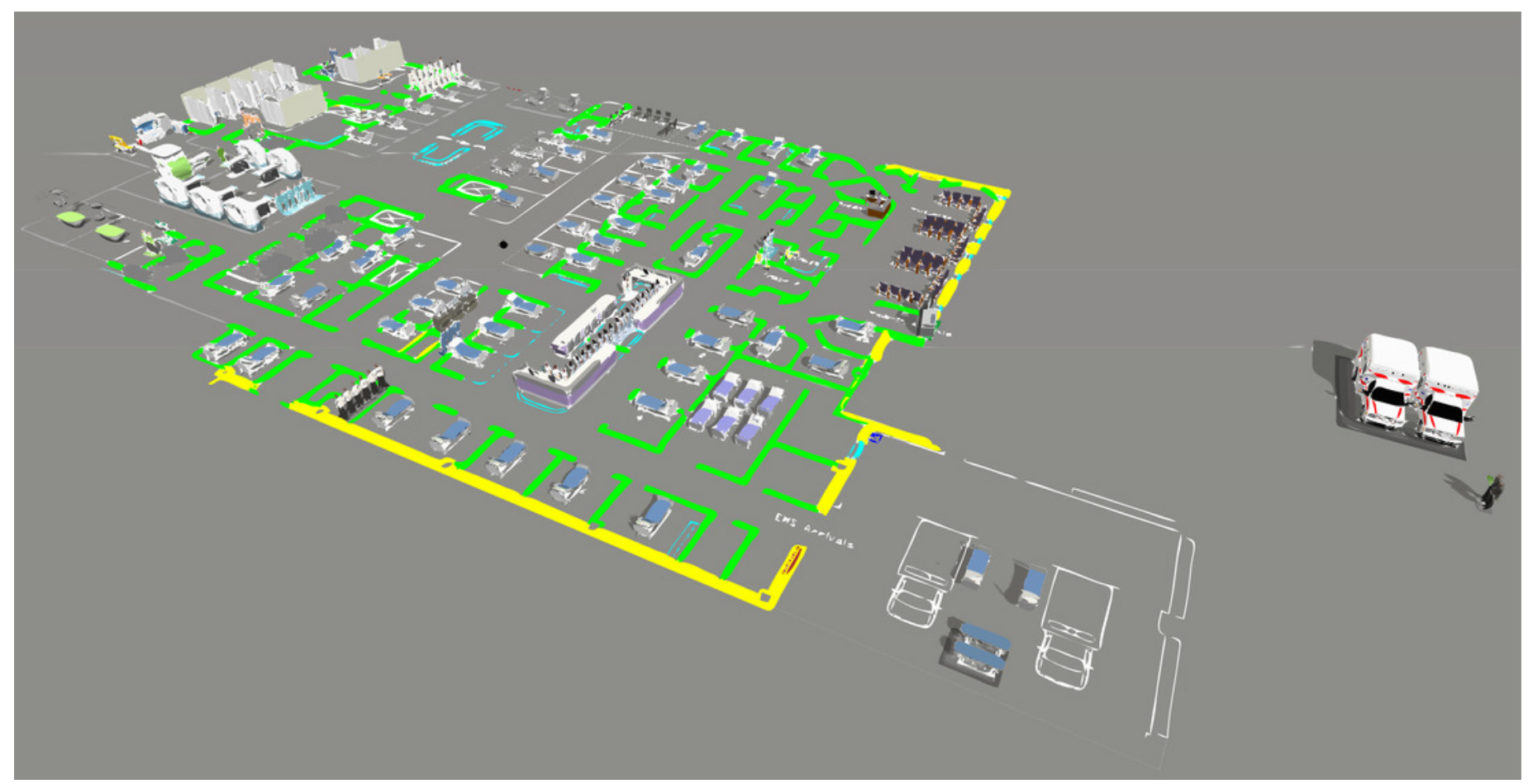


Figure 4

Figure 4. Sensitivity analysis for validation (LOS and \% Treated Patient)

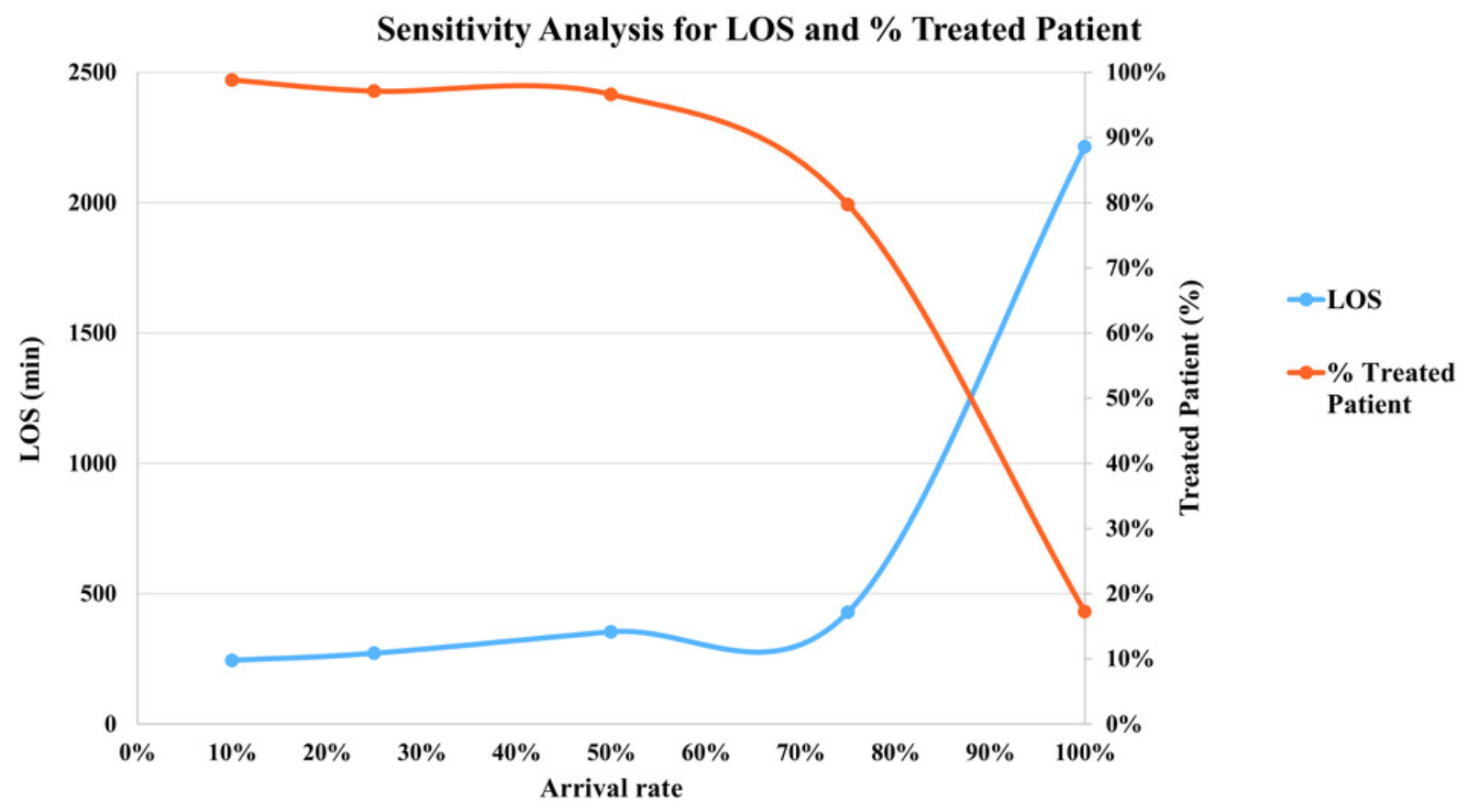

